\title{
Study On The Configuration Of Distribution Channels For New Automobiles
}

\author{
Ubiratã Tortato \\ Pontificia Universidade Católica Paraná \\ ubirata.tortato@pucpr.br \\ Roberto Marx \\ Polytechnic School, University of São Paulo \\ robemarx@usp.br
}

\begin{abstract}
This paper proposes an explanatory model for the configuration of automobile distribution channels. A case study was developed, using two sources of information: 1) the literature on the distribution of specialty goods and on automobile distribution and 2) interviews conducted with dealers and automakers. The survey allowed the identification of three variables for the proposed model: dealer size, consumer behavior and the legal environment. The model comprises three possible organizational forms for the distribution business: isolated single-brand, single-brand group, and multibrand group. This study is expected to contribute to a better understanding of the evolution of the sector, as well as to support the analysis of future auto distribution trends.
\end{abstract}

Keywords: distribution channels, automotive sector; exclusive distribution;

\section{INTRODUCTION}

In the early twentieth century, autonomous importers began to market automobiles in Brazil, mainly in Rio de Janeiro and São Paulo, its largest urban centers. At that time, the number of units sold was small, and the number of potential clients was limited. The availability of good roads, replacement parts, fuel and service stations was scarce outside the urban areas. Therefore, automobile dealers tended to concentrate in large cities during the early years.

After 1919, auto assembly began with the CKD process (Segre and Coutinho, 2001). Yet, the industry only began to grow with the arrival of foreign automakers during the 1950s. Hence it became necessary to implement a distribution system that would be compatible with the size of the country and the rapidly growing sales. The franchise system, which was already in use in USA and Europe, was adopted as a means to expand distribution.

During the 1960s and 1970s, the leading automakers in the country (Ford, GM and Volkswagen) developed an extensive dealership network that covered the entire Brazilian territory. Those major brands, later followed by Fiat, quickly implemented 400 to 800 dealerships each throughout the country. The expansion of the distribution network helped to consolidate the image of the brands among consumers, provided a more reliable supply of parts and services, and established each brand in all major markets in the country. On the other hand, the process lead to intra-brand competition, because of the proximity of many dealerships as well as because of negotiation difficulties arising from the large number of dealers in the system.

Until the early 1990s, automobiles made in Brazil were technologically outdated in comparison with the ones produced by the same automakers in Europe and the US, due to import restrictions and domestic content quotas imposed by protectionist policies. The situation benefited automakers and distributors with high profits and the absence of threats from external competition. However, the opening of Brazilian markets in the early 1990s allowed consumers to have access to a greater variety of technologically advanced products. As a result, industry and dealers 
faced a reduction in profits, and both had to undergo restructuring processes. For the automakers, the use of mechanisms such as global sourcing and supply chain management helped to achieve reductions in costs, but the distribution side still faced a challenge. After the markets opened to imports, dealer profitability gradually declined (Arbix and Veiga, 2001). As a result, some companies were forced to close or sell their operations to groups that were financially stronger, due to increased competition and a general lack of managerial capabilities to face the new market conditions.

Automobile distribution in Brazil is done by dealers which are chosen by the automakers. The relationship between the parties is regulated by a concession contract characterized as a franchise agreement. Such contracts define relations between the parties under the Federal Law that regulates the sector. For the most part, the dealerships are family-funded businesses. They face high costs related to equipment acquisition and maintenance, stocks of replacement parts and sales personnel. Revenues come from profit margins on new and used auto sales, shop services, replacement parts and other sources such as insurance and vehicle financing (Donada and Vidal, 2001).

There are currently about 2,700 auto dealers in Brazil (ANFAVEA, 2009). There are no reliable data about how many of those dealers are part of distribution groups (dealers representing one or more brands from the same corporation) and how many are isolated distributors (dealers that represent a single brand in a single geographic area). It is known, however, that the number of groups formed by acquisitions or new concessions has grown rapidly (Olmos, 2006). The major driver for the formation of distribution groups appear to be cost-related. The potential for economies of scale in new vehicle sales and the possibility of proportionally smaller investments in expensive and complex service shops would justify the formation of distribution groups (Tortato and Marx, 2004). Hence it is possible to observe changes in the configuration of new vehicle distribution channels over time. The understanding of how those changes occur can contribute to a better understanding of distribution channels for specialty goods in general. The objective of this study is to propose an explanatory model for the evolution of the configuration of distribution channels for specialty goods in general, and the case of distribution of new vehicles in particular, based on the identification of the variables involved.

\section{LITERATURE REVIEW}

When viewed in isolation, distribution in itself represents a cost for the producing organization (Bertaglia, 2005). The transfer of a product from the producer to the buyer generates costs that will be paid in the end by the consumer. For the producer, a reduction in distribution costs can result in improved competitive conditions in the consumer market. Lassar and Kerr (1996) point out that producers will ground their choice of distribution strategy on the relationship between the desired amount of control, or power, over the channel, and the resources that are required to maintain it.

The choice is also determined by the type of consumer goods, which can be classified as: convenience, comparison or specialty goods (Novaes, 2004; Lambert and Stock, 1992; Bucklin, 1963). Those three types of goods entail respectively three basic forms of distribution: intensive, selective and exclusive (Novaes, 2004; Lambert and Stock, 1992; Bucklin, 1963). These alternative forms characterize marketing channels in terms of their distribution intensity (Kotler, 2000; Mallen, 1996; Cespedes, 1988). The present case deals with specialty goods. These are typically expensive and are purchased sporadically. In general, they are associated to characteristics such as brand, prestige, quality or some specific aspect of performance. Automobiles, perfumes and designer clothes are examples of specialty goods. They usually require adequate spatial environments to receive clients, and sometimes specialized technical assistance is necessary.

The usual distribution form for specialty goods is exclusive distribution. In that case, producers generally choose one representative for each region. The relationship between producer and distributor tends to be intensive, including strong exchanges of information, training and mutual commitments. Exclusive distribution has been the choice of automakers to deliver their product to consumers. Such choice is related to the characteristics of the product, which can be classified as a specialty good (Bernheim and Whinston, 1998; Li and Dant, 1997). Automobiles are usually associated with high costs, brand name, prestige and specific performance aspects. Therefore, the maximization of results by the producer (automaker) would be obtained together with the maximization of results by the distributor, since the latter represents a single product (Coughlan et al., 2001). 
According to Grande (2004), some of the factors that may influence the determination of the structure of distribution channels are: range of customer services, social and cultural factors or consumer behavior, the legal environment, available technologies, and transaction costs. Customer service level is influenced by several factors. Kotler (2000) points out five major factors that determine service output levels: 1) Lot size: the number of units available in the channel; 2) Waiting/delivery time: average time the customers of that channel wait to get the product; 3) Spatial convenience: physical or virtual access points to the product; 4 ) Product variety: range of product assortment to serve different customers; 5) Service backup: add-on services provided by the channel, such as delivery, credit, repairs and warranty offered by the channel.

In general, the greater the range of services provided by the channel, the higher its costs. Thus the objective of many channel components is to minimize them. One of the ways is to outsource tasks, so that the channel component may concentrate on its functional abilities and become specialized (Grande, 2004).

Social and cultural aspects or consumer behavior also influence the composition of the distribution channel. Educational level, median age of the population, internal migration, changes in lifestyles, family sizes and other situations may affect directly how the distribution channel is established. The habit of testing, seeing or touching a product may be decisive for the configuration of a channel. Such situations may even justify the persistence of economically inefficient channels for long periods (Coughlan et al., 2001). Customer behavior and its changes over time may produce significant changes on distribution channels (Frazier, 1999). The attention given to factors such as service levels, social and cultural aspects reveal a specific concern with consumer behavior and seek to meet the peculiarities of the markets in which they are inserted. Therefore, when seen from the viewpoint of how the distributor is organized, the relationship among them becomes apparent. The distributor would seek a channel configuration to meet the needs of the customer (Frazier, 1999).

The legal environment may also determine the structure of a distribution channel (Coughlan et al., 2001). Different political systems or agreements may entail different ways of configuring a distribution channel. Restrictions on ownership of local companies by foreign corporations may lead to different distribution channel configurations for the same product in different countries. The prohibition of exclusive distribution contracts may lead to a similar situation, depending on the country where it is applied. In the United States, several retailers have refused to accept producer demands for exclusive distribution. Over the past eighty years, such debates have led countless producers to abandon exclusive distribution in that country (Besanko e Perry, 1993). In Europe, competition laws are being reviewed, indicating a trend towards more open distribution channels as a way to foster competition and to benefit customers.

The influence of laws appears to be directly related to the configuration of distribution channels, since the legislation creates possibilities to direct and to organize distribution structures. When laws provide clear incentives for market competition, distributors appear to seek a greater market intensity. Such is the case of the US market, in which many distributors represent the same brand in distinct points of sale, while others sell different brands in the same space.

The Internet is another influencing factor on channel structure, due to its widespread access on the part of the producer, the distributors and the final consumer. The Internet improves product commercialization, increases information flows and enhances coordination among agents in the channel (Grande, 2004; Pitt, Berthon and Berthon, 1999). The intensive use of that technology by consumers forces distributors to be well informed about the products they represent; otherwise they will be disregarded by their clients.

Transaction costs also influence the distribution channel. The transaction cost economics approach presupposes that economic agents operate in a context of bounded rationality and opportunism (Grande, 2004; Williamson, 1996). Thus companies would seek to establish governance structures to minimize transaction costs. Such costs depend on transaction attributes, asset specificity and uncertainties involved (Williamson, 1996).

The advantages associated with returns to scale achieved by organizations with higher distribution capabilities are intrinsic to transaction costs. Hence the size of distributors could contribute to reduce their basic operational costs (Williamson, 1996).

In several types of industries where relationship chains exist, there is a great probability that one of the members will shape the objectives, the division 
of labor and the ability of the agents to raise their activities in the chain (Gereffi, 2001). Humphrey and Schmitz (2001) use the term governance to express the fact that some groups in the chain determine or control the parameters that shape how the chain operates. For those authors, governance would be justified by the need of key actors to uphold their reputation in terms of quality, safety, environmental measures, labor relations and other factors, which could be compromised by other actors along the chain, in underdeveloped or developing countries.

Therefore, the decision about channel configuration can be a function of more than one of the variables described above. Conflicts may exist between components, such as cost reduction and increase in level of service. While strictly economic approaches advocate cost reductions as a way to increase competitiveness, marketing approaches advocate expanded services as a way to gain customers and increase competitiveness. Thus the levels of both costs and services offered by the organization will be conditioned by variables that are specific to the sector in question.

In all, six variables were found with the potential to compose the model: size of distributors, governance, range of services, consumer behavior, legal environment, and the use of the Internet. These variables are shown in Table 1.

\section{RESEARCH METHODOLOGY}

The research design followed a case study approach with exploratory purposes. In order to propose the explanatory model, its variables were first identified by a review of the literature, followed by semistructured interviews. The first procedure was used more intensely in the beginning of the investigation. That stage consisted of collecting information about the main themes under study, such as distribution, exclusive distribution, criteria for channel choices, and relationships along the channel. After the literature review, it was possible to identify six variables that may influence the configuration of the distribution channel. The identification of those variables was important for the preparation of the interviews for the second phase of the study.

In order to achieve a representative view of the sector, the second phase surveyed representatives from automakers and distributors, including isolated operations as well as dealers that are part of larger groups. The sample was intentional and non-probabilistic. The interviews were conducted in two stages. The interviews followed a preestablished design, but allowed a great deal of flexibility to accommodate a variety of topics. The first stage of interviews served essentially to clarify important aspects of the distribution business and to identify research possibilities. The second stage comprised interviews with representatives of three automakers and eight dealers.-

The survey population comprised the upper managerial level of automakers and distributors, including owners, directors or managers. A total of fourteen interviews were conducted with producers and dealers of the following brands that operate in the Brazilian market: Fiat, Ford, General Motors, Honda, Renault, Toyota, Volkswagen and Volvo.

The objective of the interviews was to identify the variables that the representatives from producers and dealers of new vehicles consider important for the configuration of the distribution channel. Even though the design of the semi-structured interviews was based on the literature review, the process allowed respondents to express their own views about what they perceived as important variables. The interviews allowed the identification of three variables, also present in the literature. All variables that were found during the bibliographic and field research were analyzed critically, and three variables were selected to compose the model; all of them could be identified in both research procedures.

\section{IDENTIFICATION OF VARIABLES FROM FIELD SURVEY}

After the opening of Brazilian markets in the early 1990s, the automotive sector began a process of drastic restructuring. Among the large automakers (Fiat, Ford, GM and VW) a trend to reduce the number of distributors became clear. The basic goal was to make the business more profitable. That required a reduction of margins, both for the producer and for the distributor. In addition to external competition, the entry of new automakers in the country was a threat to the established ones.

As a consequence, the market underwent more significant changes over a period of six to seven years than it had over the previous three decades. At that point the automakers began to give greater importance to the financial strength of the dealers. The ability to provide circulating capital, to support their 
vehicle quotas and to uphold their commitments became an important issue. As a result, some long established dealers found themselves under pressure. Those distributors were small-sized and often lacked focus on this specific activity. They were part of business groups that operated in other areas and for several reasons were not fully dedicated to the dealership business.

By giving particular importance to the financial strength of the distributors, the automakers were eventually faced with the formation of dealership groups. Some of these groups operated with the same brand in several locations. Others began to identify the opportunity to distribute for competing brands. That trend was opposed to what the automakers had wanted. Previously, the franchise agreements included contractual clauses to prevent dealers from selling different makes. However, due to the market circumstances at that point, involving fragmentation, increased competition and growing consumer rights protection, the automakers were forced to accept the new reality. The increase in dealership size and their consequent ability to represent other brands was a new reality that had to be accepted by the automakers.

Thus size of dealership emerges as a possible variable to influence the configuration of the distribution channel. In the early stages of the distribution business, dealerships were small, served limited areas and had few opportunities for growth. As a consequence, distributors represented a single brand and usually had only one point of sale. Over time, as some distributor groups became more capitalized and automakers intervened to reduce the number of franchises, dealerships grew larger, allowing them to represent more than one brand and also to open additional points of sale. Size may be understood as a set of characteristics related to the dealer's financial and managerial capabilities. Harbour (1996) suggests that dealership size can be classified as small (sales of up to 120 automobiles per year), medium (annual sales between 120 and 499 automobiles) or large (more than 500 automobiles per year). Hence, small-size dealers will tend to have single operations. Large-size dealers will tend to form groups and represent one or more brands. In turn, medium-size dealers may adopt either form. Size is an internal variable of the dealer and it may reflect a corporate strategy.

Another important point is that vehicle sales had long been a passive process. Customers would come to the dealership and either take what was in stock or wait for a long period to have the product they wanted. They had little ability to argue, because information was scarce. They also had little margin for negotiation because of the limited supply. With the economic opening of the early 1990s, consumer behavior changed, and so did market conditions. The increased availability of consumer goods created a different environment. A more competitive market enabled consumers to experiment and compare different products. This happened in association with increased access to information, which was due in part to the political opening of the mid-1980s and the expansion of content providers such as magazines, newspapers, radio and television programs and specialized Internet sites. Consumers obtained more information about products, began to make comparisons and to perceive the benefits and disadvantages of each vehicle, relating that to market prices.

Another aspect related to consumer behavior is Internet sales. The biggest differential of Internet sales is the reduction of some taxes, resulting in a smaller final price than the one charged in the stores. However, that also implies a smaller margin for the dealer. Yet, the field research indicated that consumers do not buy automobiles in the web, such as in the case of purchase of airline tickets or some retail goods. Consumers simply close the deal via Internet. It is the last step of a process that had several previous steps, most of them inside a dealership. Possibly because of the amount involved and the sensory needs of consumers, they must see, test, and compare the product before going to a computer terminal, often inside the store itself, to finalize the purchase.

One issue that emerged spontaneously during the survey was the significant role of women in new vehicle acquisition. Distributors are clearly aware of an increasing participation of women during the purchase process itself and in the men's decision to buy. Some previously overlooked aspects such as interior decoration of shops and service areas now receive more attention. According to some dealers, women are less keen on Internet use and express the need to try the product they are buying, similarly to what happens in a clothing store.

Therefore, consumer behavior appears to be one of the variables that affect the configuration of distribution channels. Until the early 1990s, while consumers behaved in a passive way, dealers could be organized in isolation. Due to the lack of alternatives and limited choices, consumers tended to be loyal to a given dealership, since that could mean better negotiation conditions in the future. As the market 
opened, consumers perceived new possibilities and began to give greater importance to other aspects such as variety of choice, customer service, payment conditions, access to information, performance comparisons, etc. In other words, they started to behave more actively. Under those conditions, dealers must be prepared for a customer who is not loyal and is well informed. Hence one of the solutions was to create groups that represent more than one brand as a way to "surround" the potential buyer. The consumer behavior variable is external to the dealer, upon which it does not have control.

One additional aspect that arose as important during the survey is the legal environment. The legislation about competitive conditions has evolved slowly in Brazil. That also applies to vehicle distribution. Until 1979, there were general laws that applied partially to the relations among dealerships, automakers and consumers. At the time, the country was seeking internal solutions for its development and that entailed a general neglect of incentives to competition. Thus the legislation did not stimulated competition and markets were virtually captive.

In 1979, a federal bill was passed to regulate the relationship between automakers and dealers. In fact, it established vehicle supply conditions in the country. The law as well as prevailing practices at the time regulated the distribution business very tightly. For dealers, there was a clear delimitation of profit margins, prohibition of active sales outside their territory, and other conditions that practically excluded competition within the dealership business.

However, with the market opening of the early 1990s and the associated changes in macroeconomic conditions, the law was updated. The changes in the federal law caused significant changes in the distribution sector, because market delimitation and fixed profit margins gave way to open competition. In practice, it became possible for a dealer to sell automobiles in any place of the Brazilian territory. The extinction of fixed profit margins put an end to the single automobile price in each geographical area. It was replaced by the public retail price, a sort of ceiling price for the dealer. Below that value, distributors became free to set prices according to their profit margins. That led to increased competition and even predatory tactics among distributors. Changes in the Law are now being studied to allow more operational flexibility, considering that much has changed since the early 1990s. However, any changes would have to contemplate the needs of both automakers and distributors; negotiations could take a long time and would require the mobilization of politicians around the need to revise current legislation.

Hence the Legal Environment also appears as one of the variables that affect the configuration of the distribution channel. At an early stage, when markets were restricted, the legislation benefited the isolated dealer and the single-brand representative. That benefit occurred to the extent that, under limited competition, each dealer obtained enough revenues from a small consumer base. With the changes in market conditions and increased competition, the law changed, allowing passive sales outside the dealer's area and removing restrictions to retail pricing. Under the new conditions, single-brand dealers began to face profitability problems, and the formation of multi-brand groups was intensified as a way to mitigate the problem. This variable is external to the distributor, but it may some interference upon it through its representative entities.

The three variables obtained through the field survey are summarized in Table 1.

\section{DATA ANALYSIS}

The variables obtained through both research procedures were then compared and it was observed that the three variables from the field survey were also present in the literature survey.

Thus, as described in the methodology, a critical analysis was performed with respect to each variable. That evaluation stage entailed the exclusion of three variables. In order to discard them, there were considerations about possible overlapping among variables.

The exclusion of the governance variable can be explained by the understanding among the agents that automakers in fact exert a great deal of influence over the distribution channel, but existing laws and sectoral agreements curtail that influence. That fact places this variable in a secondary position in the face of the legal environment variable. The range of services offered by dealers is the result of legal obligations and the perception of consumer needs. The variable related to Internet use is not seen as an influence in the form of organization of channels. The use of Internet is broadly seen as ancillary to the sales process, and thus it would be related to consumer behavior.

Consequently, the three remaining variables were selected to as potential components of the model: dealer 
size, legal environment, and consumer behavior.

Table 1 identifies the variables according to the source of information and indicates the ones that were eventually selected.

Table 1 - Variables resulting from literature review and field survey

\begin{tabular}{|l|l|l|l|}
\hline \multirow{2}{*}{ N. } & \multicolumn{3}{|c|}{ Variables } \\
\cline { 2 - 4 } & Literature review & Field survey & Selected \\
\hline $\mathbf{1}$ & Dealer size & Dealer size & Dealer size \\
\hline $\mathbf{2}$ & Governance & & \\
\hline $\mathbf{3}$ & Range of services & & Consumer behavior \\
\hline $\mathbf{4}$ & Consumer behavior & Consumer behavior & Legal environment \\
\hline $\mathbf{5}$ & Legal environment & Legal environment & \\
\hline $\mathbf{6}$ & Internet use & & \\
\hline
\end{tabular}

At this point, it is important to clarify the meaning and range of each variable that has been selected as well as the possible outputs of the proposed model.

1. Dealer size. Here size is understood as a set of dealer characteristics related to its financial and managerial capabilities. Harbour (1996) indicates that dealer size may be classified as small (sales of up to 120 automobiles per year), medium (sales between 120 and 499 automobiles per year) or large (sales above 500 automobiles per year). Thus small-size dealers will tend to operate in isolation; large-size dealers will tend to constitute groups and represent one or more brands; medium-size dealers would operate in any of these configurations. The size variable is the only one that is internal to the distributor and it may reflect corporate strategy.

2. Legal environment. It is understood as the legal apparatus that regulate the market, and in particular costumer-focused laws that aim to stimulate or restrict competition involving automakers and distributors. This variable is characterized as favorable or unfavorable to competition. When laws are unfavorable for competition, dealers tend to operate with a single brand, since markets tend to be captive. When laws favor competition, dealers tend to operate with several brands, because competition for customers increase. This variable is external to the distributor, but the latter may have influence its effects through political action.

3. Consumer behavior. This variable is understood as the manifestation of social, cultural, personal and psychological factors by customers (Kotler,
2000). Consumer behavior has been classified as active or passive. When consumers display a passive behavior (accepting what the market has to offer with little questioning), dealers tend to operate with a single brand. When consumers behave in an active way (seeking information, comparing offerings, etc.), dealers tend to operate with multiple brands as a way to "surround" the customer. This variable is external to the dealer, which has no control over it.

From the analysis of each variable, it is possible to observe that they affect different aspects of the configuration of the distribution channel. The two aspects under consideration are isolated operations or formation of distribution groups, and single-brand or multi-brand representation. The observed relations were the following:

1. The variable size interferes only to determine whether the distributor will operate as part of a group or in isolation.

2. The variables consumer behavior and legal environment interfere only to determine whether the distributor will represent one or more brands.

The model outputs, which are the forms of organization that distributors may assume, can be of three types:

1. Single-brand isolated: it is the dealer that represents only one brand in only one geographical area.

2. Single-brand group: it is the dealer that represents only one brand in more than one geographical area. 
3. Multi-brand group: it is the dealer that represents more than one brand in one or more geographical areas.

A consequence of the previous descriptions is the possibility to verify the combinations among the variables. Table 2 displays those combinations and the possible outputs. The table was built on the basis of the variable definitions discussed previously, as well as the adoption of some criteria for the identification of results.

Table 2 - Relations between variables and configuration of distribution channel

\begin{tabular}{|c|c|c|c|c|c|}
\hline \multicolumn{3}{|c|}{ Variables } & \multicolumn{3}{|c|}{ Configuration } \\
\hline Size & $\begin{array}{c}\text { Legal } \\
\text { environment }\end{array}$ & $\begin{array}{c}\text { Consumer } \\
\text { behavior }\end{array}$ & \# & $\begin{array}{c}\text { Single brand or } \\
\text { Multi-brand }\end{array}$ & $\begin{array}{l}\text { Isolated or } \\
\text { in Group }\end{array}$ \\
\hline Small & Unfavorable & Passive & 1 & Single brand & Isolated \\
\hline Small & Unfavorable & Active & 2 & Single brand & Isolated \\
\hline Small & Favorable & Passive & 3 & Single brand & Isolated \\
\hline Small & Favorable & Active & 4 & Single brand & Isolated \\
\hline Medium & Unfavorable & Passive & 5 & Single brand & Both \\
\hline Medium & Unfavorable & Active & 6 & Both* & Both \\
\hline Medium & Favorable & Passive & 7 & Both* & Both \\
\hline Medium & Favorable & Active & 8 & Multi-brand & Group \\
\hline Large & Unfavorable & Passive & 9 & Single brand & Group \\
\hline Large & Unfavorable & Active & 10 & Both & Group \\
\hline Large & Favorable & Passive & 11 & Both & Group \\
\hline Large & Favorable & Active & 12 & Multi-brand & Group \\
\hline
\end{tabular}

* When the dealer operates in isolation, it could be only the single-brand format.

The criteria indicate that, in order for a dealer to operate in the organizational form of a group, it must be of middle to large size. That is explained by the investments that are needed to implement points of sale and maintain a sufficient amount of working, or current, capital. In order to operate in isolation, the dealer size must be small to medium. That is justified by the need of fewer resources to maintain smaller distribution structures.

For the definition as to whether it will operate as single-brand or multi-brand distributor, the variables consumer behavior and legal environment were verified. When both variables converged to the same form of representation (single or multi-brand), the converging form was chosen. When each variable pointed to a different form of distribution, both were indicated as a possibility.

Thus all twelve possibilities of organization of newvehicle distribution are summarized in Table 2, given the possible combinations among the variables that were identified.
For the purpose of validation of Table 2, we can consider past and present situations of distribution of new vehicles.

From the 1960s to the 1980s, consumers had limited access to updated information at the moment of purchase of new products. At that time, domestic industry was unable to provide ample variety of choices to consumers. The limited number of choices entailed a passive behavior on the part of consumers that faced them. On the other hand, the legislation of that time, particularly after the second half of the 1960s, did not stimulate competition among organizations.

For that situation, the combination of variables in Table 2 that appears more apt is the number 1 (Isolated, Single-brand), which points to a possible result of an isolated dealer representing only one brand. Even in the cases where a change in dealer size occurred, towards medium or large, the final result was not significantly affected. The possible results in number 5 (Single brand and both) and number 9 (Group and Single brand) point to that possibility. 
In that situation, the dealer size is medium or large, the legal environment is unfavorable to competition, and consumer behavior is characterized as passive. Hence the dealer would be operating with a single brand, and it could either form a distribution group or operate in isolation.

However, since the mid-1990s, legislation became more favorable to competition, and consumers became more active. In addition, the number of dealers that were able to expand their size increased, as well as the process of formation of dealership groups, both single- and multi-brand. On the other hand, those that were unable to adapt to the new market conditions either left the business or were absorbed by the new groups. In this situation, depending on dealer size, the model points to the organization forms classified as number 4 (isolated, single-brand), 8 (group, multi-brand) and 12 (group, multi-brand).

After the 1990s, the small size dealers began to face problems, particularly with allocations of costs, and the formation of single-brand and multi-brand groups expanded rapidly. This intensification of conglomerate distribution groups is observed today. In general, as dealer size grows, the formation and expansion of groups seem inevitable.

Hence, after establishing the possible combinations of variables and the verification of their implications for the results, the representation of the proposed relations is displayed in Figure 1. In addition, there is a clear need to point out the possible consequences related to different configurations of the distribution channel.

The adoption of professional management is one of the changes. Initially, distribution management was performed by family members or by someone they trusted. With the rise of distribution groups, came the need to implement professional management practices by hiring specialists or by developing managerial capabilities among business heirs. Thus it can be inferred that the formation of multi-brand or single-brand groups tends to increase the adoption of professional management, while it tend to decrease among isolated distributors

Another important consequence is the increase on bargaining power of the distributor in relation to the automaker. Initially, distributors were isolated and dealt with a single brand. Hence, their power relative to the automaker was relatively small. With the formation of distributor groups and the expansion of their share in total automaker sales, the power relationship tends to change, even if the automaker retains governance of the chain. Hence it can be suggested that the formation of multi-brand or singlebrand groups tends to increase distributor power in relation to the automaker, while it tends to decrease among isolated dealers. 


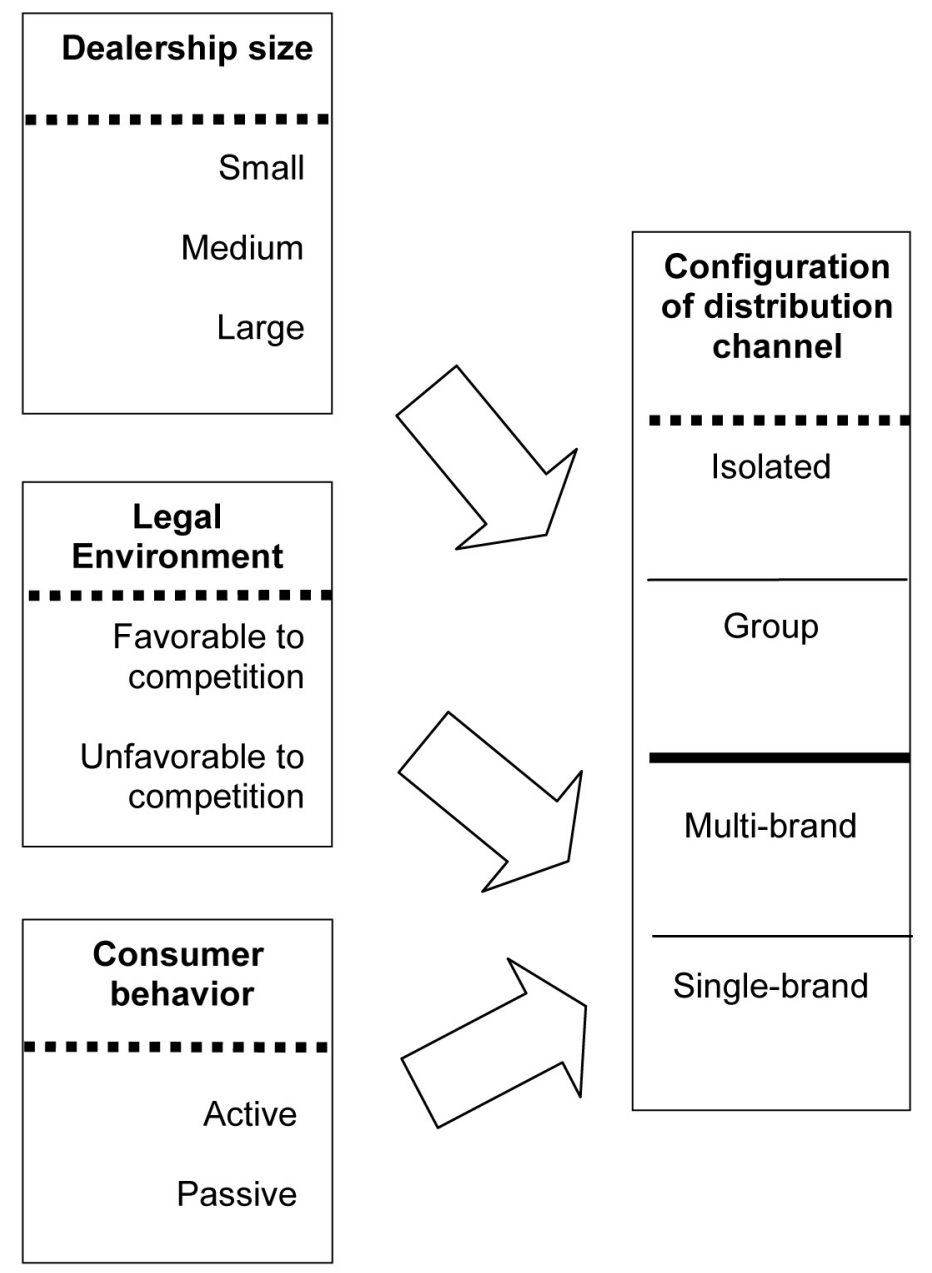

Figure 1 - Explanatory model for the configuration of new-vehicle distribution channel

Lastly, another important consequence is the reduction of distributor costs. In isolated dealers, costs related to managerial activities, shop maintenance, sales promotion and inventories have a proportionally larger impact on business results. With the formation of groups, such costs are optimized by sharing resources. Consequently, the formation of multi-brand or single-brand groups tends to reduce costs for the distributor, and they tend to increase for isolated dealers.

Those three possible outcomes, for their turn, provide feedback to the system. They have a particular impact on the dealer size variable. The increase in professional management, in bargaining power visa-vis the automaker, and the reduction in distributor costs tend to reinforce positively the increase in dealer size. The inverse also applies. The other two variables, legal environment and consumer behavior, tend to be more effectively influenced by exter- nal factors, which can also influence to some degree the dealer size variable.

\section{FINAL REMARKS}

The automobile distribution sector in Brazil, similarly to what is observed worldwide, is characterized by a slow rate of innovation. It is a sector in which practically only domestic companies operate, and in which the Internet, despite its promises and the theoretical potential to transform the business, has had little effect. In addition, despite all the crises that have affected the sector in recent years, the logic of doing business and its practices remain basically unchanged for decades.

This study shows some indications that such situation is likely to change in the near future as a result of the concentration process in the distribution business, as well as the intensification of a trend toward 
multi-brand representation. It is also possible to observe changes in the relationship between dealers and automakers. The imposing stance from the part of automakers has given way to economic rationality.

Thus the objective of this study was to propose an explanatory model for the configuration of distribution channels of new vehicles. The aspect of configuration was approached by looking at the choices between operating in isolation or as part of the group, and between dealing with one brand or multiple brands.

From the literature and field survey, three variables with the potential to affect the model were identified. They are: dealer size, consumer behavior and legal environment. Among the three variables, only dealer size is controlled by the organization itself, the others are open to external control. Consumer behavior is hardly amenable to intervention, and the legal environment demands action through entities that represent the automotive sector.

Hence Figure 1 proposed an explanatory model for organization forms of new vehicle distribution. The proposal implies that a model to explain the configuration of new vehicle distribution channels could help to shed light on concepts about distribution, in particular the distribution of specialty goods, and more specifically in the case of automobiles. Within the automotive sector, the model is also helpful to understand the entire chain, due to its focus in the issue that has been subject of few academic studies: the distribution. The model can also be useful as an ancillary tool for strategic planning, either for automakers or for dealerships that may foresee possible changes in the proposed variables.

\section{REFERENCES}

ANFAVEA.(2009), Anuário da indústria automobilística brasileira. São Paulo: ANFAVEA. Available in: http://www.anfavea. com.br/anuario2009/indice.pdf, in: 02/08/2010.

ARBIX, G.; VEIGA, J. P. (2001), A distribuição de veículos sob fogo cruzado: em busca de um novo equilíbrio de poder no setor automotivo. Available in: http://www.fenabrave.org.br, in: $01 / 30 / 2007$.

BERNHEIM, B. D.; WHINSTON, Michael. (1998), Exclusive dealing. The Journal of Political Economy, v. 106, n.1, p. 64103, February.

BERTAGLIA, P. R. (2005), Logística e gerenciamento da cadeia de abastecimento. São Paulo: Saraiva.

BESANKO, David; PERRY, Martin. (1993), Equilibrium incentives for exclusive dealing in a differentiated products oligopoly. RAND Journal of Economics, V. 24, n. 4, p. 646-667, winter.

BUCKLIN, L. (1963), Retail strategy and the classification of con- sumer goods, Journal of Marketing, V. 27. n. 1, p.50-55.

CESPEDES, Frank. (1988), Channel management is general management. California Management Review, V. 31, n. 1, p. 98-120, fall.

COUGHLAN, A.; ANDERSON, E.; STERN, L.; EL-ANSARY, A. (2001), Marketing Channels. Upper Saddle River: Prentice Hall.

DONADA, C.; VIDAL, O. (2001), Des concessions automobiles en quête d'une stratégie marketing. Decisions Marketing, $\mathrm{n}^{\mathrm{o}}$ 23, mai-août, p. 65-73.

FRAZIER, Gary. (1999), Organizing and managing channels of distribution. Journal of the Academy of Marketing Science, v. 27 , n.2, p. 226-240, spring.

GEREFFI, Gary. (2001), Shifting governance structures in global commodity chains, with special reference to the internet. American Behavioral Scientist, v.44, no. 10, p.1616-1637, june.

GRANDE, M. M. (2004), A distribuição de automóveis novos em mudança? Estudo a partir de survey e pesquisa qualitativa em concessionárias. São Paulo: Escola Politécnica da Universidade de São Paulo, Thesis.

HARBOUR, M. (1996), Automotive distribution in Brazil, ICDP Research Paper, nº 9/96.

HUMPHREY, J.; SCHMITZ, H. (2001), Governance in global value chains, IDS Bulletin, V. 32, n.3, p. 41-52.

LAMBERT, Douglas; STOCK, James. (1992), Strategic logistics management. Boston: MacGraw-Hill.

LASSAR, W.; KERR, J. (1996), Strategy and control in supplierdistributor relationships: an agency perspective, Strategic Management Journal, V.17, n. 8, p. 613-632, October.

LI, Zhan; DANT, Rajiv. (1997), An exploratory study of exclusive dealing in channel relationships. Journal of the Academy of Marketing Science, v. 25, n.3, p. 201-213,summer.

MALLEN, Bruce. (1996), Selecting channels of distribution: a multi-stage process. International Journal of Physical Distribution \& Logistics Management, V. 26, n. 5, p. 5-21.

NOVAES, A. G. (2004), Logística e gerenciamento da cadeia de distribuição. Rio de Janeiro: Campus.

OLMOS, M. (2006), Revendedor de veículos adota modelo multimarcas. Jornal Valor Econômico, São Paulo, 04/24/2006.

PITT L, BERTHON P, BERTHON J P. (1999), Changing channels: the impact of the Internet on distribution strategy. Business Horizons, Mar-Apr, Vol 42, No 2.

SEGRE, L. M.; COUTINHO, M. T. (2001), De l'importance de la vente et du service apres-vente dans l'industrie automobile bresilienne: etute sur la fidelisation de marque, la formation et la qualification des ressources humaines. IX Gerpisa International Coloquium, Paris, Gerpisa, 2001 (CD-ROM).

TORTATO, U.; MARX, R. (2004), Distribuição de Automóveis no Brasil: questões sobre estratégias futuras do modelo. 17ํㅜ Congresso Latino-Americano de Estratégia, SLADE, 28 - 30 April, 2004, Itapema, SC, Brazil.

WILLIAMSON, O. (1996), Mechanisms of governance. New York: Oxford University Press. 


\section{Author's Biography}

Ubiratã Tortato holds a Doctor degree in Production Engineering from Polytechnic School, University of São Paulo, Brazil. He also holds a Master degree in Business Administration from the Federal University of Paraná. He is currently an associate professor at the Graduate School of Business of Pontificia Universidade Católica do Paraná. His research interests involve logistics and supply chain management and sustainability.

Roberto Marx holds a Doctor and Master degree in Production Engineering from Polytechnic School, University of São Paulo, Brazil. He is currently an associate professor at Production Engineering Department, Polytechnic School, University of São Paulo, Brazil. He is a researcher and member of the GERPISA International Network (Permanent Group for the Study of the Automobile Industry and its Employees). His research interests involve automobile industry and work group's organization. 